\title{
Interpreting pleural fluid results 缆
}

\author{
Authors: Rachel M Mercer, ${ }^{\mathrm{A}}$ John P Corcoran, ${ }^{\mathrm{B}}$ Jose M Porcel, ${ }^{\mathrm{C}}$ Najib M Rahman ${ }^{\mathrm{D}}$ and Ioannis Psallidas ${ }^{\mathrm{E}}$
}

Interpreting pleural fluid results correctly requires an awareness of the possible aetiologies of a pleural effusion and an understanding of the reliability of the outcome of each investigation. All results must be interpreted within each different clinical context and knowledge of the pitfalls for each test is necessary when the diagnosis is unclear. This review aims to discuss the common aetiologies of a pleural effusion and some of the pitfalls in interpretation that can occur when the diagnosis is unclear.

KEYWORDS: Pleural effusion, pleural infection, malignant pleural effusion, biomarkers

\section{Introduction}

Pleural effusions are a common clinical and radiological finding, with presenting symptoms that include shortness of breath, cough and chest pain. The most common causes of a pleural effusion are heart failure, cancer and pneumonia but there are over 50 documented causes. ${ }^{1}$ Diagnosing the cause of a pleural effusion requires a combination of clinical, radiological and laboratory investigations.

Pleural fluid (PF) accumulation is a result of disruption in the balance between production and reabsorption. PF is produced primarily by the parietal pleura and reabsorbed via the pleural lymphatics. In healthy individuals, the pleural cavity contains approximately $0.3 \mathrm{~mL} / \mathrm{kg}$ of fluid. ${ }^{2}$ A pleural effusion occurs either when production exceeds reabsorption or when the mechanisms of reabsorption have been disrupted, the latter being more common.

An understanding of the clinical situation is vital when investigating the cause of a pleural effusion. In patients with known congestive cardiac failure (CCF) and bilateral effusions, it is highly likely that this is the cause of the effusions. ${ }^{3}$ Unless there is a suspicion of dual pathologies, which are more common than previously thought, ${ }^{4}$ diuresis should be undertaken rather than

Authors: ${ }^{\mathrm{A}}$ clinical fellow, University of Oxford, Oxford, UK and Oxford University Hospitals NHS Trust, Oxford, UK; ${ }^{B}$ consultant chest physician, University Hospitals Plymouth NHS Trust, Plymouth, UK; ${ }^{\text {P }}$ professor of medicine, Arnau de Vilanova University Hospital,

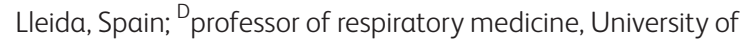
Oxford, Oxford, UK and Oxford University Hospitals NHS Trust, Oxford, UK; ${ }^{\mathrm{E}}$ consultant chest physician, University of Oxford, Oxford, UK and Oxford University Hospitals NHS Trust, Oxford, UK

immediate thoracentesis, with a subsequent review to confirm treatment response. ${ }^{3}$ Conversely, patients with an effusion and high inflammatory markers, fevers or chest pain should always have thoracentesis due to the possibility of pleural infection.

Radiology can also aid in making a diagnosis; an ultrasound showing an echogenic, septated collection with air bubbles, raises the possibility of pleural infection. There are also several computed tomography (CT) criteria suggesting malignant pleural disease $\mathrm{e}^{5}$ and so a pleural effusion in this context would be highly suspicious for a malignant pleural effusion (MPE).

Many pleural effusions will not have a clear aetiology, so interpretation of the PF results, in addition to clinical and radiological information, is essential in making a diagnosis (Table 1). A standard panel of tests includes PF protein, glucose, $\mathrm{pH}$, lactate dehydrogenase (LDH), cytology and microbiology. Interpreting these results requires some knowledge of the sensitivity and specificity of these tests and an understanding of the physiology and supporting evidence.

\section{Transudate vs exudate}

Differentiating between a transudative and exudative effusion is pivotal in identifying the underlying process. The key difference

Table 1. Differential diagnosis of pleural fluid results

\section{PF results}

Low glucose and/or high LDH

provels

Very low protein $(<15 \mathrm{~g} / \mathrm{dL})$

Lymphocyte predominance

Neutrophil predominance

Eosinophil predominance

\section{Common causes}

Pleural infection, MPE, rheumatoid effusion, oesophageal rupture, lupus pleuritis and, at times, TPE

Exudative effusion and any aetiology, very high levels are often caused by TB

Dural leak, urinothorax, entrapped lung

TPE, lymphoma, post cardiac bypass graft, renal or liver failure, rheumatoid arthritis, rarely PPE

PPE, early TPE, less commonly due to pulmonary embolism or pancreatitis

MPE, idiopathic and PPE

$\mathrm{LDH}=$ lactate dehydrogenase; $\mathrm{MPE}=$ malignant pleural effusion; $\mathrm{PF}=$ pleura fluid; $P P E=$ parapneumonic effusions; $T B=$ tuberculosis; $T P E=$ tuberculous pleural effusion 
between a transudative and exudative effusion is how the PF has accumulated. A transudate is almost always associated with an imbalance of fluid or protein throughout the body, rather than a specific pleural pathology. It can be produced in two ways; firstly, from fluid overload, where the hydrostatic pressure forces the fluid out of the capillaries and into the extravascular space, such as in CCF. Secondly, decreased oncotic pressure in the capillaries can lead to fluid being leached out of the vessels and again accumulating in the extravascular space; this is found in low albumin states such as liver failure or nephrotic syndrome.

An exudative effusion, conversely, is usually caused by a disease localised to the pleura. Leakage of fluid is due to increased capillary permeability triggered by an insult such as infection or malignancy.

\section{Pleural fluid lactate dehydrogenase}

LDH is a marker of inflammation or cellular injury, so is a sensitive, but non-specific pathological marker. ${ }^{6} \mathrm{LDH}$ levels of greater than three times the upper limit of normal (often $>1,000 \mathrm{U} / \mathrm{L}$ ) are often indicative of pleural infection, in the appropriate clinical scenario. ${ }^{7}$ This can also be associated with rheumatoid pleurisy, tuberculous pleurisy ${ }^{7}$ or malignancy. ${ }^{8}$

\section{Light's criteria}

In 1972, Dr Richard Light published a study producing criteria that have a high sensitivity and specificity for differentiating transudative from exudative effusions using their biochemical results. The original criteria to diagnose a biochemically exudative effusion was one or more of a PF to serum protein ratio greater than 0.5 , a PF LDH of greater than $200 \mathrm{IU}$ and a PF to LDH ratio greater than $0.6{ }^{9}$ The PF LDH level was later modified to more than two-thirds of the upper limit of the normal LDH level. ${ }^{10}$ Any one of these criteria being present, predicts an exudative effusion with a $94.7 \%$ accuracy, ${ }^{11}$ although the criteria have a lower specificity, so it is more common to misclassify a transudate as an exudate rather than vice versa. This is important, so causes of exudative effusions, such as MPE, are less likely to be missed. Serum to PF albumin levels, or the total protein gradient may be calculated and potentially used to reclassify apparently exudative effusions which are clinically more likely to have a transudative aetiology.

\section{Discordant results}

There are times when the PF results can be misleading, and results should always be interpreted with the clinical context in mind. Some examples are described in Table 2.

\section{Cell differential}

A high lymphocyte count is most commonly associated with a tuberculous pleural effusion (TPE), but chronic effusions can often have a high lymphocyte ratio of $50 \%$ or more. The most common aetiologies which produce lymphocytic effusions are tuberculosis (TB), malignancy and CCF. Other aetiologies include lymphoma and post-cardiac bypass graft, renal or liver failure, rheumatoid arthritis and rarely parapneumonic effusions (PPE). ${ }^{13}$

A neutrophil count of $>50 \%$ of the total leukocyte count is commonly seen with PPEs, ${ }^{14}$ but it has been shown that about $10 \%$ of tuberculous effusions can also be neutrophil predominant.
Table 2. Factors which can confound pleural fluid

interpretation

\begin{tabular}{|c|c|c|}
\hline Biomarker & Confounder & Results \\
\hline PF protein & $\begin{array}{l}\text { Diuretic } \\
\text { therapy }\end{array}$ & $\begin{array}{l}\text { Concentrated pleural } \\
\text { effusion causing a higher } \\
\text { level of PF protein or LDH } \\
\text { and, therefore, leading to } \\
\text { a misclassification as an } \\
\text { exudate }\end{array}$ \\
\hline \multirow[t]{3}{*}{$\mathrm{PF} \mathrm{pH}^{12}$} & $\begin{array}{l}\text { Air, time delay } \\
\text { in processing }\end{array}$ & $\begin{array}{l}\text { Falsely elevates } \mathrm{pH} \text {, all air } \\
\text { should be expelled from } \\
\text { the syringe and processing } \\
\text { should occur within } 4 \text { hours }\end{array}$ \\
\hline & $\begin{array}{l}\text { Local } \\
\text { anaesthetic }\end{array}$ & Falsely lowers the $\mathrm{pH}$ \\
\hline & Loculations & $\begin{array}{l}\text { Different locules of a pleural } \\
\text { effusion can have different } \\
\text { pH measurements }\end{array}$ \\
\hline PF microbiology & Contaminants & $\begin{array}{l}\text { Skin commensals are } \\
\text { occasionally cultured in PF. } \\
\text { Positive PF cultures should } \\
\text { be interpreted with caution } \\
\text { if the biochemical PF results } \\
\text { and clinical picture are not in } \\
\text { keeping with infection }\end{array}$ \\
\hline
\end{tabular}

A systematic review including 687 patients with an eosinophilic effusion the most common underlying diagnoses were malignancy (26\%), idiopathic (25\%) and PPE (13\%), but the likelihood of malignancy was lower as the levels of eosinophilia increased. ${ }^{15}$ The predominant cell type is rarely diagnostic of an underlying aetiology, but it can help contribute to the clinical picture in cases where the cause of the effusion is unclear.

\section{Diagnostic tests}

There are a small number of pathologies where PF results can be diagnostic of the aetiology of an effusion. These are described in Table 3.

Amylase in the PF, which has not been specifically tested for its different isoenzyme forms is not diagnostic of one aetiology alone but is highly sensitive for either oesophageal rupture, pancreatic disease or malignancy. Levels of over 10,000 IU/L can be found in patients with a pancreaticopleural fistula but any level of amylase in the pleural fluid which is above the reference range for serum is considered abnormal. ${ }^{20}$

While a number of the tests mentioned have a very high specificity and are considered diagnostic, many have a low sensitivity. A number of these aetiologies, such as pleural infection and MPE can be diagnosed using a combination of the pleural fluid results and clinical picture, which will be discussed later in the article.

\section{Transudative effusions}

Transudative effusions are very common but have few specific tests. It is not always necessary to obtain a sample of PF if 
Table 3. Diagnostic pleural fluid biomarkers

\begin{tabular}{|c|c|c|}
\hline Pathology & Aetiology & Diagnostic tests \\
\hline Haemothorax & $\begin{array}{l}\text { Frank blood in the pleural } \\
\text { space, normally as a } \\
\text { result of trauma }\end{array}$ & $\begin{array}{l}\text { Haematocrit PF } \\
\text { level of }>0.5 \text { that } \\
\text { of the serum }{ }^{14}\end{array}$ \\
\hline \multirow[t]{2}{*}{ Chylothorax (Fig 1) } & \multirow[t]{2}{*}{$\begin{array}{l}\text { Damage to the thoracic } \\
\text { duct causing a chyle leak } \\
\text { into the pleural space }\end{array}$} & $\begin{array}{l}\text { Presence of } \\
\text { chylomicrons is } \\
\text { diagnostic }\end{array}$ \\
\hline & & $\begin{array}{l}\text { Triglyceride levels } \\
\text { of }>110 \mathrm{mg} / \mathrm{dL} \\
(>1.24 \mathrm{mmol} / \mathrm{L})^{16}\end{array}$ \\
\hline \multirow[t]{2}{*}{ Pseudochylothorax } & \multirow{2}{*}{$\begin{array}{l}\text { High levels of cholesterol, } \\
\text { common in tuberculous } \\
\text { and rheumatoid related } \\
\text { effusions }\end{array}$} & $\begin{array}{l}\text { Presence of } \\
\text { cholesterol } \\
\text { crystals }\end{array}$ \\
\hline & & $\begin{array}{l}\text { Cholesterol/ } \\
\text { triglyceride level } \\
\text { of }>1^{17}\end{array}$ \\
\hline MPE & $\begin{array}{l}\text { Fluid accumulation } \\
\text { caused by primary or } \\
\text { secondary malignancies. }\end{array}$ & $\begin{array}{l}\text { PF cytology or } \\
\text { pleural biopsies } \\
\text { showing } \\
\text { malignant cells }\end{array}$ \\
\hline Pleural infection & $\begin{array}{l}\text { Frank pus or infected } \\
\text { fluid in the pleural space }\end{array}$ & $\begin{array}{l}\text { Visual } \\
\text { confirmation of } \\
\text { pus or positive } \\
\text { microbiological } \\
\text { culture } \\
\text { (including } \\
\text { Mycobacterium } \\
\text { tuberculosis) }\end{array}$ \\
\hline Urinothorax & $\begin{array}{l}\text { Due to traumatic } \\
\text { damage to the urinary } \\
\text { system or obstructive } \\
\text { uropathy }\end{array}$ & $\begin{array}{l}\text { PF/serum } \\
\text { creatinine ratio } \\
\text { of }>1 \text { with a } \\
\mathrm{pH} \text { lower than } \\
7.30^{18}\end{array}$ \\
\hline Pancreatic disease & $\begin{array}{l}\text { Any damage to the } \\
\text { pancreas can result in a } \\
\text { pleural effusion }\end{array}$ & $\begin{array}{l}\text { PF amylase } \\
>110 \mathrm{U} / \mathrm{L} \text { (only } \\
\text { diagnostic if there } \\
\text { is a predominant } \\
\text { pancreatic } \\
\text { isoenzyme } \\
\text { profile) }\end{array}$ \\
\hline
\end{tabular}

$\mathrm{MPE}=$ malignant pleural effusion; $\mathrm{PF}=$ pleural fluid

the effusions are bilateral and there is a systemic condition which would explain them. CCF is the most prevalent cause of a transudative effusion (about $80 \%$ of the cases) but other common causes include cirrhosis, hypoalbuminaemia and peritoneal dialysis. ${ }^{7}$ Rarer causes include hypothyroidism, nephrotic syndrome, constrictive pericarditis, urinothorax and Meigs' syndrome. $^{21}$

\section{Heart failure}

Patients who have known CCF, bilateral, small to moderate pleural effusions without fever, chest pain and leukocytosis, can be treated with diuresis rather than needing immediate thoracentesis,

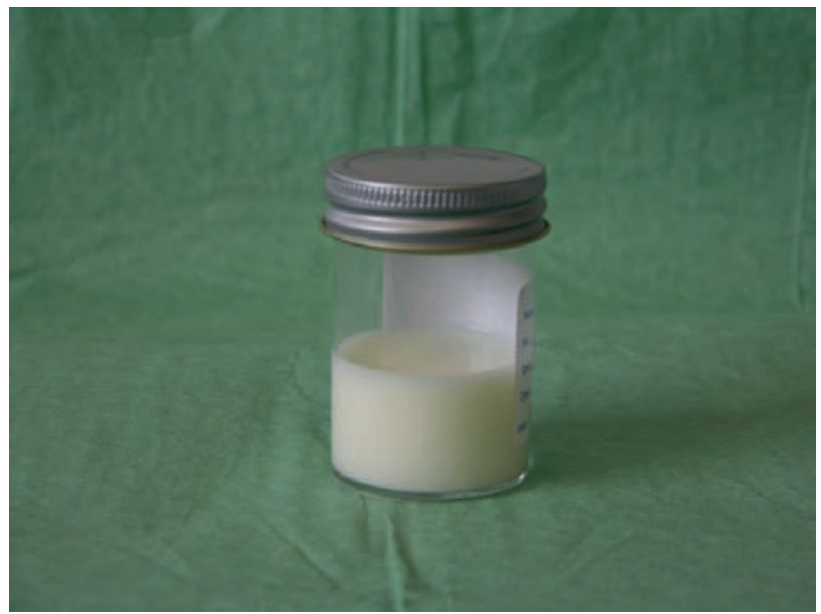

Fig 1. Sample of chyle

with subsequent evaluation of clinical response. ${ }^{3} \mathrm{~A}$ therapeutic thoracentesis, however, can be performed for symptomatic relief in patients with large cardiac effusions.

In patients with CCF, pleural effusions are bilateral in $58 \%$ of patients, $27 \%$ are right sided and $14 \%$ left sided. ${ }^{22}$ If sampling is undertaken these effusions are traditionally transudative but misdiagnosis can occur in the case of bloody effusions or with diuretic use, causing a concentrated effusion.

$\mathrm{N}$ terminal - pro-brain natriuretic peptide (NT-proBNP) in PF can also be used to help support a diagnosis of a CCF related effusion. A meta-analysis of 10 studies found the pooled sensitivities and specificities were both $94 \%$, but there was also a high correlation between serum and PF NT-proBNP. ${ }^{23}$ This suggests that, unless dual pathologies are suspected, PF testing may offer little that serum results could not provide.

\section{Exudative effusions}

\section{Pleural infection}

Pleural infection has a high mortality ${ }^{24}$ and an infected pleural space should be drained promptly to improve the patient's morbidity and mortality. ${ }^{25,26}$

The gold standard for diagnosis of pleural infection is the growth of an organism in the PF. Unfortunately, $40 \%$ of aspirates are negative in standard culture, ${ }^{24}$ but the yield is increased with the simultaneous use of blood culture bottles. ${ }^{27}$ The addition of pleural biopsy culture may further increase microbiological yield, ${ }^{28}$ but this requires further evaluation given the additionally invasive nature of the technique. The decision regarding whether the pleural space is infected cannot be based on culture alone due to the low diagnostic yield and the time taken for an organism to be cultured.

Biochemical markers are used to differentiate between a complicated parapneumonic effusion (CPPE) which needs prompt drainage and a simple or uncomplicated PPE which is likely to resolve with antibiotics alone. A CPPE is defined by a $\mathrm{PF} \mathrm{pH}<7.2$ but also can include glucose $<3.4 \mathrm{mmol} / \mathrm{L}(<61 \mathrm{mg} / \mathrm{dL})$ and LDH $>1000$ if $\mathrm{pH}$ is not available. ${ }^{24,29}$

Ultrasound findings are relevant for pleural infection as in heavily septated or loculated effusions, the biochemical results can be different in the discrete areas, so can give falsely 
reassuring results. ${ }^{30}$ Effusions are also sometimes referred to as sonographically complex, which is an echogenic effusion with or without septations. ${ }^{31}$ A sonographically complex effusion was $69.2 \%$ sensitive and $90 \%$ specific in predicting a CPPE in one study, ${ }^{31}$ but this sensitivity is too low to replace thoracentesis.

PF biochemistry is the primary diagnostic tool for pleural infection due to the ability to deliver prompt results and the impact on management strategies, ${ }^{29}$ but the investigations must always be interpreted in the appropriate clinical context as some MPE or inflammatory effusions can produce similar biochemical results. Ultrasound is not sensitive enough to replace thoracentesis when pleural infection is suspected. If in doubt, erring on the side of caution and treating for pleural infection, is often the right course of action while awaiting the microbiological culture and regularly assessing the patient's clinical state.

\section{Tuberculous pleural effusion}

There is a high incidence of tuberculous pleurisy worldwide, but there is significant variation in different geographical areas. TPE often presents subacutely with a fever and chest pain but will also normally resolve without treatment in around $4-16$ weeks. This can generate an incorrect assumption that the pathology has resolved, which can lead to a delay in TB diagnosis. ${ }^{32}$ The effusion is often caused by a delayed hypersensitivity reaction rather than an acute bacterial empyema, which may explain the poor diagnostic yield.

The gold standard for diagnosis of a TPE is a positive microscopy and/or culture of Mycobacterium tuberculosis in PF or biopsies. Culturing Mycobacterium is a lengthy process and has been reported to have a modest diagnostic yield in $\mathrm{PF}$ of $<30 \%$. ${ }^{32-34}$ Biopsies have a higher diagnostic yield ${ }^{35}$ and the diagnosis is often made, in the correct clinical context, after granulomas are noted on pleural biopsy, rather than acid fast bacilli being identified. TPE classically has high lymphocyte (around $80 \%$ ), glucose $<5.6 \mathrm{mmol} / \mathrm{L}$, high protein (half of patients have levels above $50 \mathrm{~g} / \mathrm{dL}$ ) and high LDH levels (>500 IU/L in $75 \%$ of cases). ${ }^{7}$

Adenosine deaminase (ADA) is a marker of immune reactions within lymphocytes ${ }^{36}$ and is used to help diagnose a TPE. In low risk areas (prevalence of $\mathrm{TB}<125 / 100,000$ population), an ADA $<40 \mathrm{IU} / \mathrm{L}$ can effectively rule out TPE in $97-98 \%$ of patients. ${ }^{13,37}$ In moderate to high-risk populations an ADA level of $\geq 35-40 \mathrm{IU} / \mathrm{L}$ can be used to diagnose TPE with $92 \%$ sensitivity and $90 \%$ specificity. ${ }^{38}$ False positive results can be found in empyemas, rheumatoid effusions, malignancy and other infectious diseases. ${ }^{39}$

\section{Malignant pleural effusion}

The gold standard for diagnosis of MPE is positive PF cytology or pleural biopsy. The yield for cytology is around $60 \%{ }^{21}$ The majority of MPEs will be detected within two attempts at sampling and further specimens are unlikely to yield new positive results. ${ }^{40}$ The British Thoracic Society guidelines suggest that a sample of at least $50 \mathrm{~mL}$ of PF should be sent for cytological testing. ${ }^{21}$ The most common types of malignancies to cause a MPE are lung (37\%), breast $(16 \%)$, haematological $(10 \%)$ and unknown primary $(10 \%)$. $^{41}$

Serum tumour markers are used in clinical practice for screening, diagnosis, prognosis and management in a number of malignancies, ${ }^{42}$ but PF tumour markers are not routinely used in clinical practice. One study used a combination of four PF tumour markers which were assessed as being the most clinically relevant and found that the with $100 \%$ specificity there was only $54 \%$ sensitivity for predicting malignancy. ${ }^{43}$

If pleural thickening is identified on CT, a pleural biopsy can be offered which is reported to have between a $85-93 \%$ sensitivity with $100 \%$ specificity. ${ }^{21}$ Pleural biopsies are obtained through image guided techniques, such as CT or ultrasound, or via thoracoscopy.

Despite these techniques there are still some patients in whom it is not possible to obtain a definite malignant diagnosis, but in which the clinical suspicion is still high. A cytology negative, exudative effusion, in the context of known malignancy, is normally managed as an MPE unless an alternative diagnosis is identified.

\section{Malignant mesothelioma}

Mesothelioma is an aggressive and usually incurable cancer of the pleura almost exclusively related to asbestos exposure. The importance of diagnosis with this condition is both clinical and financial as a diagnosis of mesothelioma is often related to a previous occupation and the patients can be eligible for financial compensation. The yield from PF cytology is low and biopsies are usually needed. ${ }^{21}$

\section{Predictive scores in pleural diseases}

There are a number of algorithms that have been developed over the last few years to establish factors which are predictors of morbidity and mortality. For patients with MPE, the LENT (pleural fluid lactate dehydrogenase, Eastern Cooperative Oncology Group performance score, neutrophil-to-lymphocyte ratio and tumour type) score uses PF values and performance status to predict survival. ${ }^{44}$ More recently, the PROMISE (survival and pleurodesis response markers in malignant pleural effusion) score was developed which estimates the risk of 3-month mortality in patients with MPE using a larger combination of biomarkers. ${ }^{45}$ The RAPID (renal, age, purulence, infection source, and dietary factors) score predicts 3 month mortality in patients with pleural infection. ${ }^{46}$ Although some of these scores have been validated in larger practice, their clinical utility in day-to-day decision making is yet to be established.

\section{Conclusions}

Knowledge regarding the interpretation of PF results is vital to effectively manage patients with pleural effusions. Although the sensitivity and specificity of many of the most commonly used tests is high, there is always a small proportion of false positives and false negatives. PF results are a key part of the clinical assessment, but all results must be interpreted in the context of the patient in front of you, to allow for accurate diagnosis and management.

\section{References}

1 Sahn SA HJ. Pleural fluid analysis. In: Light RW, Lee YCG (eds). Textbook of pleural diseases, 2nd edn. London: Arnold Press, 2008:209e26.

2 Miserocchi G. Physiology and pathophysiology of pleural fluid turnover. Eur Respir ] 1997;10:219-25.

3 Johnson JL. Pleural effusions in cardiovascular disease. Pearls for correlating the evidence with the cause. Postgrad Med 2000;107:95-101;quiz 257. 
4 Walker S, Maskell N. Identification and management of pleural effusions of multiple aetiologies. Curr Opin Pulm Med 2017:23:339-45.

5 Traill ZC, Davies RJ, Gleeson FV. Thoracic computed tomography in patients with suspected malignant pleural effusions. Clin Radiol 2001;56:193-6.

6 Drent M, Cobben NA, Henderson RF, Wouters EF, van Dieijen-Visser M. Usefulness of lactate dehydrogenase and its isoenzymes as indicators of lung damage or inflammation. Eur Respir ] 1996;9:1736-42.

7 Light RW, Gary LY. Textbook of pleural disease, 3rd edn. London: CRC Press, 2016.

8 Verma A, Phua CK, Sim WY et al. Pleural LDH as a prognostic marker in adenocarcinoma lung with malignant pleural effusion. Medicine 2016:95:e3996.

9 Light RW, Macgregor MI, Luchsinger PC, Jr Ball WC. Pleural effusions: the diagnostic separation of transudates and exudates. Ann Intern Med 1972;77:507-13.

10 Light RW. Pleural diseases, 3rd edn. Baltimore: Williams \& Wilkins, 1995.

11 Vives M, Porcel JM, Vicente de Vera M, Ribelles E, Rubio M. A study of Light's criteria and possible modifications for distinguishing exudative from transudative pleural effusions. Chest 1996;109:1503-7.

12 Mishra EK, Rahman NM. Factors influencing the measurement of pleural fluid pH. Curr Opin Pulm Med 2009;15:353-7.

13 Jimenez Castro D, Diaz Nuevo G, Perez-Rodriguez E, Light RW. Diagnostic value of adenosine deaminase in nontuberculous lymphocytic pleural effusions. Eur Respir ] 2003;21:220-4.

14 Porcel JM, Azzopardi M, Koegelenberg CF, Maldonado F, Rahman NM, Lee YC. The diagnosis of pleural effusions. Expert Rev Respir Med 2015;9:801-15.

15 Oba Y, Abu-Salah T. The prevalence and diagnostic significance of eosinophilic pleural effusions: a meta-analysis and systematic review. Respiration 2012;83:198-208.

16 Hillerdal G. Chylothorax and pseudochylothorax. Eur Respir ] 1997;10:1157-62.

17 Lama A, Ferreiro L, Toubes ME et al. Characteristics of patients with pseudochylothorax-a systematic review. J Thorac Dis 2016;8:2093101.

18 Garcia-Pachon E, Romero S. Urinothorax: a new approach. Curr Opin Pulm Med 2006;12:259-63.

19 Joseph J, Viney S, Beck B et al. A prospective study of amylaserich pleural effusions with special reference to amylase isoenzyme analysis. Chest 1992;102:1455-9.

20 Sahn SA. Getting the most from pleural fluid analysis. Respirology 2012;17:270-7.

21 Hooper C, Lee YC, Maskell N. Investigation of a unilateral pleural effusion in adults: British Thoracic Society Pleural Disease Guideline 2010. Thorax 2010;65(Suppl 2):ii4-17.

22 Morales-Rull JL, Bielsa S, Conde-Martel A et al. Pleural effusions in acute decompensated heart failure: Prevalence and prognostic implications. Eur J Intern Med 2018;52:49-53.

23 Janda S, Swiston J. Diagnostic accuracy of pleural fluid NT-pro-BNP for pleural effusions of cardiac origin: a systematic review and meta-analysis. BMC Pulm Med 2010;10:58.

24 Davies HE, Davies RJ, Davies CW. Management of pleural infection in adults: British Thoracic Society Pleural Disease Guideline 2010. Thorax 2010;65(Suppl 2):ii41-53.

25 Sasse S, Nguyen TK, Mulligan M et al. The effects of early chest tube placement on empyema resolution. Chest 1997;111:1679-83.

26 Corcoran JP, Wrightson JM, Belcher E et al. Pleural infection: past, present, and future directions. Lancet Respir Med 2015;3:563-77.

27 Menzies SM, Rahman NM, Wrightson JM et al. Blood culture bottle culture of pleural fluid in pleural infection. Thorax 2011;66:658-62.
28 Psallidas I, Kanellakis NI, Bhatnagar R et al. A pilot feasibility study in establishing the role of ultrasound-guided pleural biopsies in pleural infection (the AUDIO study). Chest 2018;154:766-72.

29 Heffner JE, Brown LK, Barbieri C, DeLeo JM. Pleural fluid chemical analysis in parapneumonic effusions. A meta-analysis. Am J Respir Crit Care Med 1995;151:1700-8.

30 Maskell NA, Gleeson FV, Darby M, Davies RJ. Diagnostically significant variations in pleural fluid $\mathrm{pH}$ in loculated parapneumonic effusions. Chest 2004;126:2022-4.

31 Svigals PZ, Chopra A, Ravenel JG, Nietert PJ, Huggins JT. The accuracy of pleural ultrasonography in diagnosing complicated parapneumonic pleural effusions. Thorax 2017;72:94-5.

32 Gopi A, Madhavan SM, Sharma SK, Sahn SA. Diagnosis and treatment of tuberculous pleural effusion in 2006. Chest 2007;131:880-9.

33 Bielsa S, Palma R, Pardina M et al. Comparison of polymorphonuclear-and lymphocyte-rich tuberculous pleural effusions. Int J Tuberc Lung Dis 2013;17:85-9.

34 Escudero Bueno C, Garcia Clemente M, Cuesta Castro B et al. Cytologic and bacteriologic analysis of fluid and pleural biopsy specimens with Cope's needle. Study of 414 patients. Arch Intern Med 1990;150:1190-4

35 Diacon AH, Van de Wal BW, Wyser C et al. Diagnostic tools in tuberculous pleurisy: a direct comparative study. Eur Respir ] 2003;22:589-91.

36 Internal Clinical Guidelines Team. Tuberculosis: Prevention, diagnosis, management and service organisation. London: NICE, 2016.

37 Lee YC, Rogers JT, Rodriguez RM, Miller KD, Light RW. Adenosine deaminase levels in nontuberculous lymphocytic pleural effusions. Chest 2001;120:356-61.

38 Porcel JM. Advances in the diagnosis of tuberculous pleuritis. Ann Transl Med 2016;4:282.

39 Porcel JM. Tuberculous pleural effusion. Lung 2009;187:263-70.

40 Garcia LW, Ducatman BS, Wang HH. The value of multiple fluid specimens in the cytological diagnosis of malignancy. Mod Pathol 1994;7:665-8.

41 Porcel JM, Esquerda A, Vives M, Bielsa S. Etiology of pleural effusions: analysis of more than 3,000 consecutive thoracenteses. Arch Bronconeumol 2014:50:161-5.

42 Duffy MJ. Tumor markers in clinical practice: a review focusing on common solid cancers. Med Princ Pract 2013;22:4-11.

43 Porcel JM, Vives M, Esquerda A et al. Use of a panel of tumor markers (carcinoembryonic antigen, cancer antigen 125, carbohydrate antigen 15-3, and cytokeratin 19 fragments) in pleural fluid for the differential diagnosis of benign and malignant effusions. Chest 2004;126:1757-63.

44 Clive AO, Kahan BC, Hooper CE et al. Predicting survival in malignant pleural effusion: development and validation of the LENT prognostic score. Thorax 2014;69:1098-104.

45 Psallidas I, Kanellakis NI, Gerry S et al. Development and validation of response markers to predict survival and pleurodesis success in patients with malignant pleural effusion (PROMISE): a multicohort analysis. Lancet Oncol 2018;19:930-9.

46 Rahman NM, Kahan BC, Miller RF et al. A clinical score (RAPID) to identify those at risk for poor outcome at presentation in patients with pleural infection. Chest 2014;145:848-55.

Address for correspondence: Dr Rachel M Mercer, University of Oxford Respiratory Trials Unit, Churchill Hospital, Oxford OX3 7LE, UK.

Email: rachel.mercer@nhs.net 